\title{
Determining Research and Development Expenditure Targets Based on an Affordability Index
}

\author{
David R. Walwyn ${ }^{1}$ \\ ${ }^{1}$ School of Engineering and Technology Management \\ University of Pretoria
}

\begin{abstract}
Gross domestic expenditure on research and development (GERD), usually expressed as a percentage of gross domestic product (GDP), is a widely used indicator to reflect the research intensity within a national economy, and hence its capacity to develop new and innovative products or services. It is also used as a key target in the management of national innovation systems. For instance, the South African National Research and Development Strategy set a target of raising GERD/GDP to 'somewhat over 1\%', and in 2002 the Barcelona European Council set an EU target of 3\%. Despite its widespread usage, there is little discussion or agreement on how this target should be derived within a broad range of economic contexts and levels of affordability. In this paper, a composite indicator based on GERD/GDP, normalised for GDP per capita, is developed and its use in a number of countries explored and explained. As a result, a set of GERD/GDP targets for various categories of developing countries is proposed.
\end{abstract}

Keywords: gross domestic expenditure, research and development; indicators; developing countries; investment target

\section{Introduction}

On the $23^{\text {rd }}$ August 2006, Mr S Dithebe, a South African Member of Parliament, requested from the Minister of Science and Technology, Minister Mangena, a verbal reply to the following question:

"Whether he will persuade Cabinet to adopt a much more rigorous approach to achieve all of the objectives of the National System of Innovation by revising the amount spent in respect of the Gross Domestic Product (GDP) and research and development (R\&D) by 2008 . If not, why not; if so, what are the relevant details?"

In his reply, the Minister stated:

"Yes, in part. The goal of $1 \%$ of GDP on R\&D spending has always been considered an interim target. This spending comes from three main sources: the business sector, public expenditure and international funding. The setting of a higher goal has merit in that we do not see the $1 \%$ as an end in itself, but an indicator and benchmark of our national commitment to becoming a knowledge economy. To achieve a target of $1.6 \%$ by 2008 would require (based on the 2004/5 R\&D survey) an extra R10 billion of annual expenditure from business, government and international sources. In our view, this level of new expenditure cannot be fully absorbed by 2008 . We consider it more prudent to place such a target for 2010 or 2011.” 
The question by Mr Dithebe raised an important issue for science policy in South Africa. When the South African National Research and Development Strategy [1] set a target of 'somewhat over 1\%' for gross domestic expenditure on R\&D (GERD)/GDP, how was this figure obtained? Why not $1.25 \%$ or $1.5 \%$, or even $0.96 \%$ ? In this article, a composite approach is developed that can be used to determine in a semi-quantitative, and yet relatively simple, manner an appropriate level for GERD/GDP for a range of countries.

\section{Background Information on GERD/GDP}

Surveys of the research and development activities within a specific country have become commonplace. Subsequent to the development of the Frascati Manual [6], and the regular publication of national statistics by the Organisation for Economic Cooperation and Development (OECD), the data quality and its inter-comparability have also improved.

GERD, often expressed as a percentage of GDP, is one of the more important indicators for the measurement of national R\&D intensity and in some respects as an indicator of the relative innovation capability within developed countries. Its use was first proposed in the mid 1960s when the OECD began to look more closely at the factors driving technology development [4]. Its obvious utility has resulted in its widespread adoption within national statistics and GERD/GDP is a core part of the output from national R\&D surveys and also inter-country comparisons. As an example of is importance in policy decisions, the European Union has recently adopted a target of 3\% (GERD/GDP) at the Barcelona European Council of 2002 [2].

The economic and social returns from $R \& D$ expenditure have been extensively studied and there is now broad acceptance that these returns are significantly positive in most contexts [8]. Given the prospect of a positive return, what are the factors that constrain GERD? What prevents national governments in particular from allocating far higher levels to publicly funded research programmes than we currently observe, especially in developing countries?

The answer lies mostly in labour constraints, absorption capacity within national systems of innovation and more immediate priorities for public funds. Increased funding does not necessarily translate into higher impact; instead it can result in a higher cost of research for the same output. Given the competing demands for public funds, varying levels of affordability and the need to maximise research output from the available resources, governments must balance a number of factors in reaching its target for GERD/GDP. A generic approach to achieving this balance and setting a realistic target within the affordability limits of any country, but particularly developing countries, is now proposed.

\section{Historical GERD Data}

Data on GERD is available from a number of sources, of which the most comprehensive is that published on a biannual basis by the OECD in the form of its 'Main Science and Technology Indicators' [5]. The organisation has been collecting data on a systematic basis since the early 1960s, and its tables include in addition to GERD, data on GDP, purchasing power parity (PPP) and R\&D employment. 
The data shows that different countries have widely different levels of GERD, both in absolute terms and expressed as a percentage of GDP (see Figure 1; data for 2003). It is noted that the absolute levels of GERD have been converted to US\$ and also corrected for the relative purchasing powers of each national currency. The latter correction, which is based on purchasing power parity, is a standard approach followed by the OECD in the analysis of national data. The approach requires the initial conversion of the 2003 GERD (or GDP) from the relevant national currency to US\$, followed by the adjustment for purchasing power to give GERD in \$ PPP 2003 (values for PPP can be obtained from [5]).

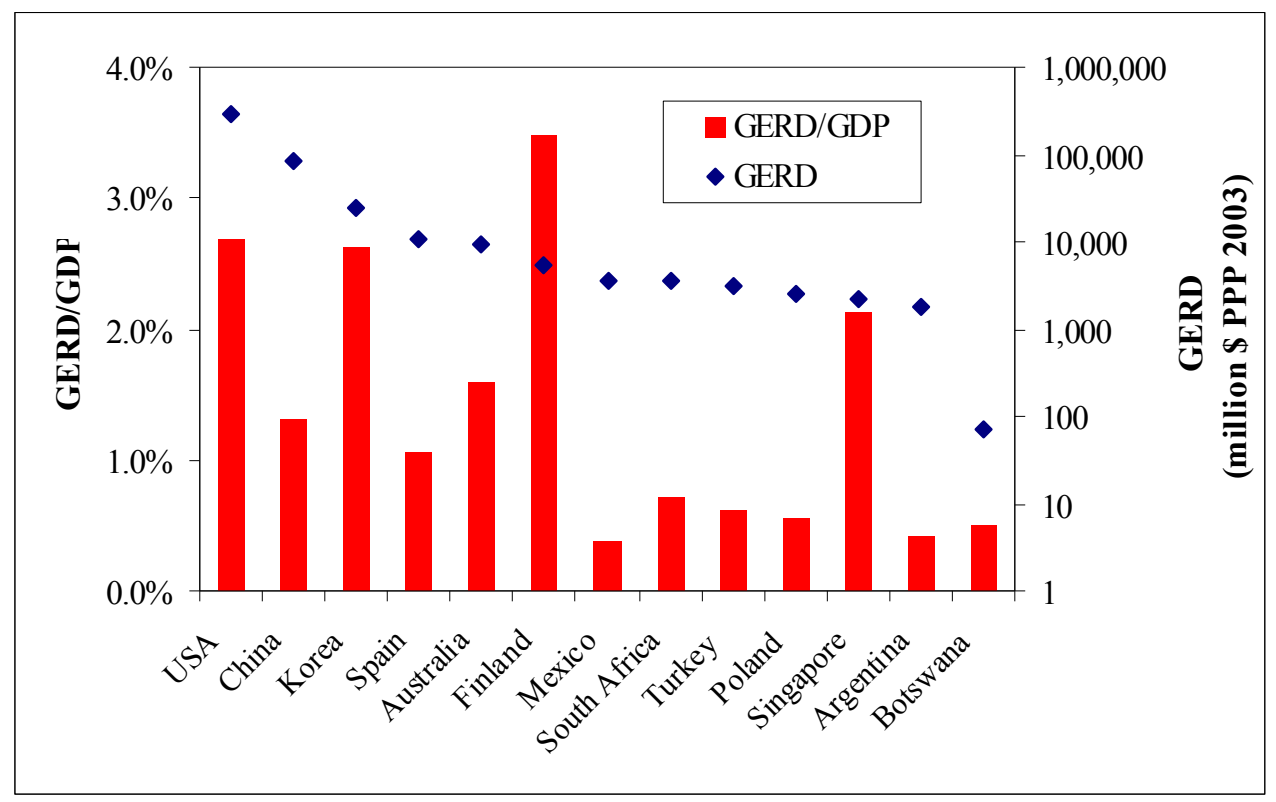

Figure 1. GERD (PPP 2003) and GERD/GDP data for a number of countries

In addition to inter-country variability within any single year, the values also vary considerably from year to year, with most countries having gradually increased their GERD over the last thirty years. The wide variation reflects differences in the availability of both public and private funds to support $R \& D$, and the capacity of a national system of innovation to absorb these funds in a productive manner. In determining the appropriate target for GERD/GDP, it is useful to study the historical GERD data for countries which have been successful in making the transition from low income, poorly developed economies to the knowledge-based economies of the $21^{\text {st }}$ century, such as Korea and Finland.

This data confirms that such countries have historically supported GERD at above average levels. Such inter-country comparisons, however, must be undertaken using normalised data, in order to remove differences in GDP and public sector spending levels; this normalisation is performed using GDP/capita (expressed as \$ PPP per head of population. GERD/GDP is a dimensionless parameter and therefore not influenced by exchange rate, inflation or purchasing power effects. However GDP/capita needs to be adjusted for exchange rate and purchasing power, hence the conversion to \$ PPP 2003. Examples of GERD, GDP and GDP/capita for selected countries are given in Table 1. 
Many studies have shown that GERD/GDP generally increases with rising levels of per capita income (see Figure 2) [3]. In other words the higher the level of economic activity or 'national wealth', the greater the investment in R\&D. GERD/GDP is therefore often more a function of affordability than of economic policy and it is broadly correct to conclude that research intensity is determined by levels of national income.

Table 1. Examples of country level statistics extracted from the OECD database

\begin{tabular}{|l|c|c|c|c|c|}
\hline Country & $\begin{array}{c}\text { Population } \\
\mathbf{( 1 0 0 0 s ;} \\
\text { 2003) }\end{array}$ & $\begin{array}{c}\text { GDP } \\
\text { (million \$ } \\
\text { PPP 2003) }\end{array}$ & $\begin{array}{c}\text { GERD } \\
\text { (million \$ } \\
\text { PPP 2003) }\end{array}$ & $\begin{array}{c}\text { GDP/capita } \\
\text { (million \$ PPP } \\
\text { 2003/head) }\end{array}$ & $\begin{array}{c}\text { GERD/ } \\
\text { GDP }\end{array}$ \\
\hline Argentina & 38005 & 437763 & 1795 & 11519 & $0.41 \%$ \\
\hline Finland & 5213 & 149554 & 5205 & 28689 & $3.48 \%$ \\
\hline USA & 291085 & 10918500 & 292437 & 37510 & $2.68 \%$ \\
\hline Korea & 47849 & 922485 & 24274 & 19279 & $2.63 \%$ \\
\hline China & 1292270 & 6446342 & 84647 & 4988 & $1.31 \%$ \\
\hline
\end{tabular}

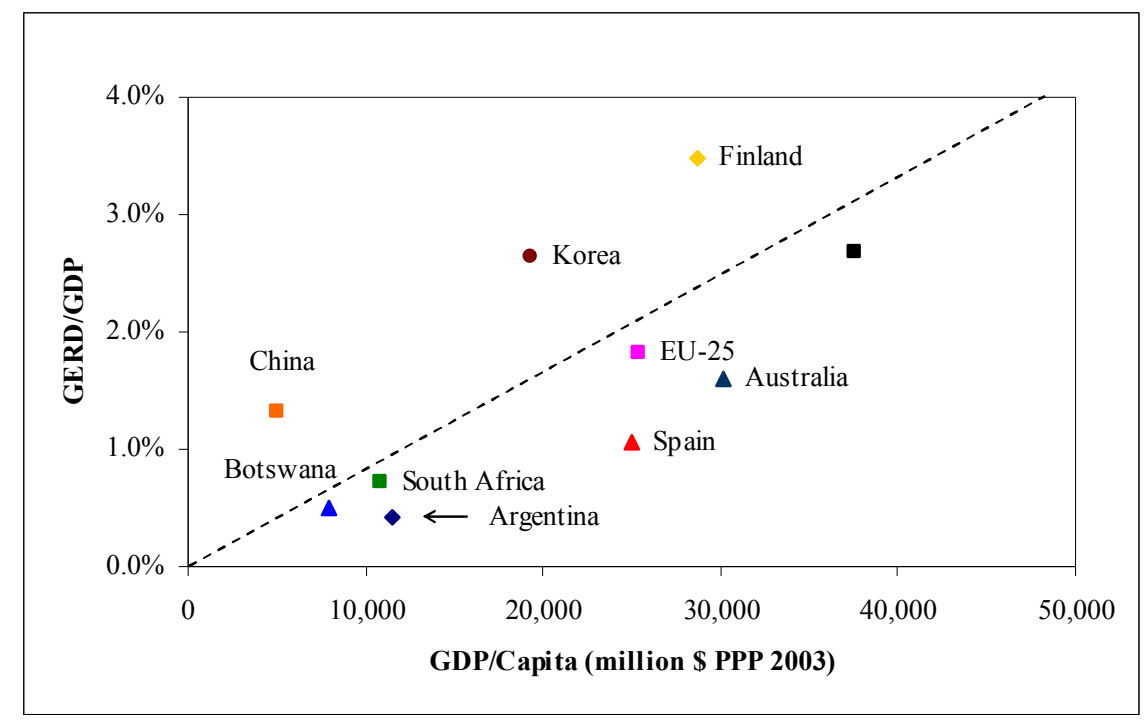

Figure 2. 2003 research intensity and GDP per capita for various countries

\section{The Development of a Composite Indicator}

The relationship between GERD/GDP and GDP/capita could be used as a basis for setting a national target for GERD or GERD/GDP. In other words, having expressed GDP per capita on a strictly comparative basis, GERD/GDP can be determined from the 'best in class' relationship between GERD/GDP and GDP per capita, as extracted from the historical data. The underlying assumption in this approach is that one can learn from the historical investment patterns of the leading countries, which have often followed more aggressive R\&D spending patterns that that of their peers.

However, it is not appropriate to make such comparisons over such a broad range of countries, as indicated in Figure 2. Countries at certain points of their development trajectories should consider an R\&D allocation in excess of the average level. The question is 'how much more?' Is it possible using this approach to develop a semi- 
quantitative approach which can offer a more definitive guideline for financial planners within national treasuries?

Such information can be extracted from the data by its conversion to a composite indicator, as explained in the following section. The first step is to express the data in the form of the composite index:

$$
I_{R I}=(\mathrm{GERD} / \mathrm{GDP}) /(\mathrm{GDP} / \mathrm{Capita}) * 10^{6}
$$

$I_{R I}$ varies typically over a range from 0.3 to 3.0 , depending on the R\&D intensity relative to GDP within any single country. It is noted that the index is sensitive to the base year which is used for the calculation of GDP/capita; in this article all data is referenced to the year 2003. The proposed indicator can be used in several ways including as a means of rapidly identifying those countries that have a bolder, more research focussed development strategy as opposed to the countries which are substantially under-investing (see Figure 3).

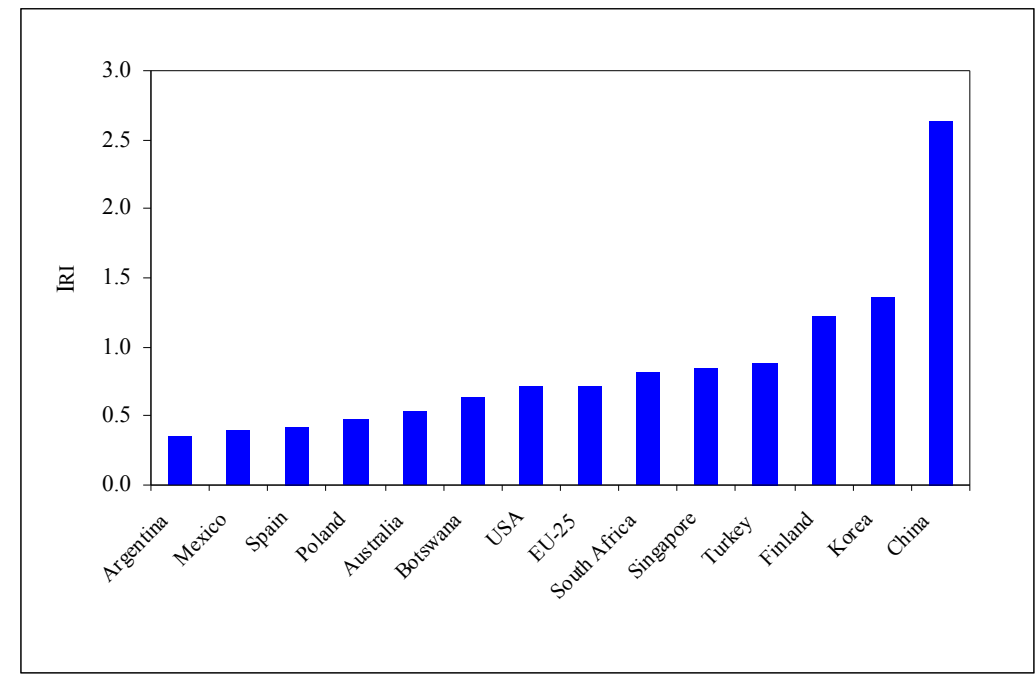

Figure 3. Country values of $I_{R I}$ for the year 2003

It is clear that China has chosen a highly research intensive development strategy, whereas Argentina is investing far below the average across a range of countries. The analysis of the index $I_{R I}$ raises a more interesting question, which is whether there is an optimum, or even a recommended minimum.

This question can be answered by a more in depth study of time series data for $I_{R I}$. Using the OECD data, we can calculate the profile of changes in the index over a twenty year period. Once again GERD/GDP is a dimensionless parameter and can be used without adjustment. However GDP per capita must be adjusted for inflation to ensure that the comparison is based on real and not nominal values. Such time series information was calculated for a number of countries and is shown in Figure 4 (all values for GDP/capita have been converted to \$ PPP 2003). 


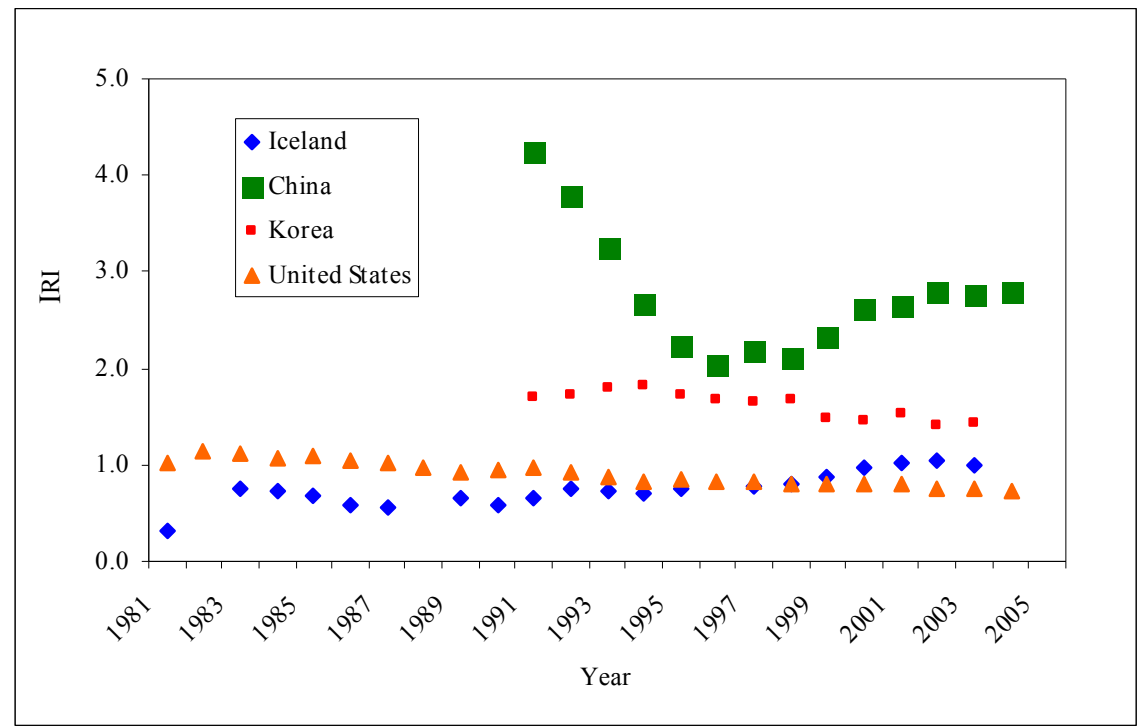

Figure 4. Values for $I_{R I}$ over the period 1981 to 2005 for a number of countries

The figure shows that the index varies depending on the research investment policy within any single country. Furthermore, the economic performance of the sample countries, as measured by GDP growth, does indeed correlate with $\mathrm{I}_{\mathrm{RI}}$ if one allows a three year time lag between investment in $\mathrm{R} \& \mathrm{D}$, as measured by $\mathrm{I}_{\mathrm{RI}}$, and the resultant economic activity (see Figure 5).

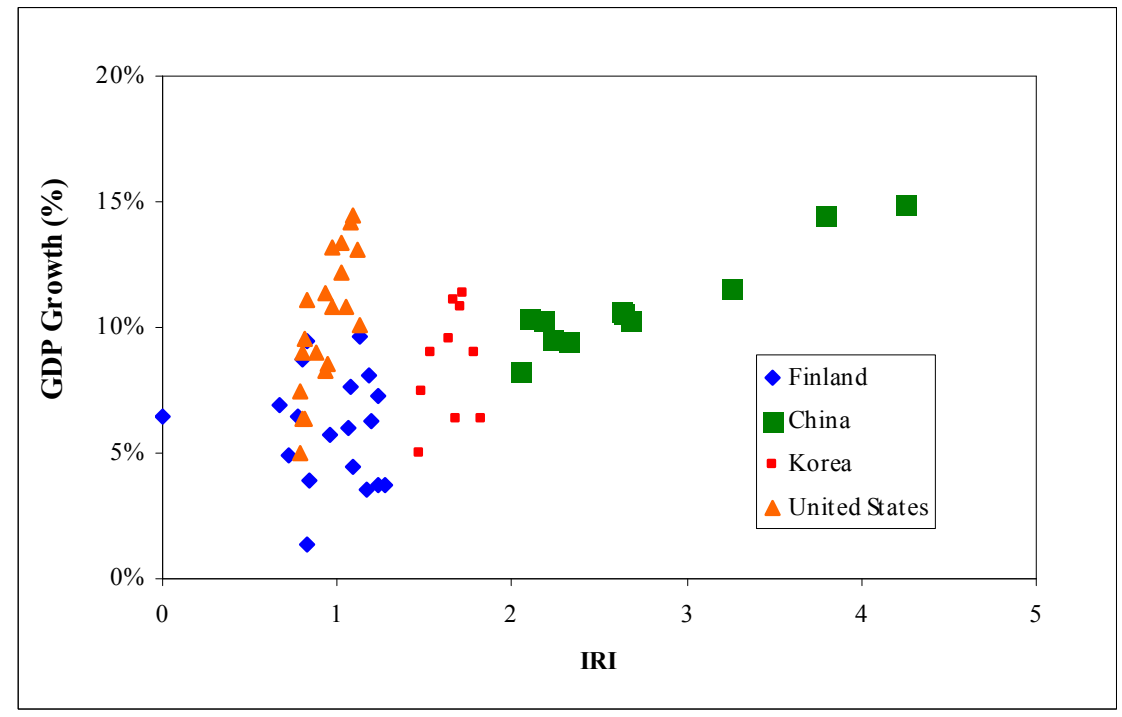

Figure 5. Growth in GDP vs $I_{R I}$ over the period 1981 to 2005 for a number of countries

Although many attempts have been made to establish a link between GERD and economic growth [7], such studies are complicated by the many external factors which can simultaneously influence GDP such as commodity prices and labour market fluctuations. As a result, a direct correlation between GERD and GDP is neither likely nor easily demonstrated, except under certain conditions. For instance, the unique contribution to the Finnish economy by the emergence of the cell phone industry has been used in an unambiguous way to demonstrate the return on investment in R\&D for both the public and the business sector [10]. 
On the basis of the data shown in Figure 5, it is possible to make certain recommendations as to the required value of $I_{R I}$, depending on the existing GDP per capita and the economic history of the country. These values are defined in Table 2.

Table 2. Suggested values for $I_{R I}$ as a function of GDP/capita

\begin{tabular}{|l|c|c|}
\hline Category & $\begin{array}{c}\text { GDP/capita limits } \\
\text { (million \$ PPP 2003) }\end{array}$ & $\begin{array}{c}\text { Recommended } \\
\boldsymbol{I}_{\boldsymbol{R}}\end{array}$ \\
\hline Less Developed Country & $<10000$ & $0.8-1.2$ \\
\hline Innovative Developing & $\begin{array}{c}000<\mathrm{GDP} / \text { capita } \\
\text { Country }\end{array}$ & 1.5 \\
\hline Developed Country & $>20000$ & $\sim 1$ \\
\hline
\end{tabular}

Following the guidelines, the recommended levels of GERD/GDP for a number of countries, as compared to the existing levels, are given in Table 3. The targets are higher for most countries, with the exception of Finland which appears under the proposed guidelines to be over-investing in research. The implication for many developing countries, and in particular the Innovative Developing Countries, is that the higher levels of research intensity are required in order to ensure that such countries can on a sustainable basis build research capacity and hence the innovative capability of their domestic economies.

The values for $\mathrm{I}_{\mathrm{RI}}$ as stated in Table 3 are not intended to replace the more rigorous approaches based on dynamic equilibrium or multifactor productivities, but rather as initial 'rules of thumb' which can be used by policy makers in the absence of the detailed economic data required for more complex models. Indeed for many developing countries this data is in any case not available and a more approximate approach which is supported by the type of benchmark study presented in this article.

Finally, it is noted that a key factor in allocating resources to national R\&D is the capacity of its institutions to absorb the funding and deliver innovative goods and services. Without the necessary human resources and infrastructure, increased research intensity is a glorious but worthless objective. It must be matched by simultaneous alignment of the training of skilled human resources and the construction of the necessary research institutions. Furthermore, the proposed approach to setting a target for GDP/GERD is not a substitute for thorough ex-post evaluation; the latter is essential in determining the impact on such parameters as multi-factor productivity through changing levels of R\&D expenditure.

\section{Conclusion}

The composite indicator, $I_{R I}$, has been defined and quantified for several countries based on published data. Moreover its change over time has been analysed and correlated with GDP. The analysis has suggested a set of research strategies for national policy makers, depending on the country's economic wealth. In particular, it is recommended that Less Developed Countries should raise $I_{R I}$ to at least a value of 0.8 to 1.2 , that Innovative Developing Countries, should maintain $I_{R I}$ at a value of between 1 and 2 for a period of about ten years, and that the developed countries should stabilise $I_{R I}$ at about 1 . These investment strategies should enable most countries to achieve the desired levels of innovation and economic growth on the 
condition that attention is simultaneously paid to the country's research infrastructure and required human capital.

Table 3. Recommended levels of GERD/GDP for a number of countries (and the EU-25)

\begin{tabular}{|l|c|c|}
\hline Country & $\begin{array}{c}\text { Latest Available } \\
\text { GERD/GDP } \\
\mathbf{( \% )}\end{array}$ & $\begin{array}{c}\text { Recommended } \\
\text { GERD/GDP } \\
\mathbf{( \% )}\end{array}$ \\
\hline Botswana $[9]$ & 0.50 & 0.79 \\
\hline South Africa & 0.87 & 1.62 \\
\hline Mexico & 0.39 & 1.43 \\
\hline Australia & 1.69 & 3.01 \\
\hline EU-25 & 1.82 & 2.53 \\
\hline USA & 2.68 & 3.75 \\
\hline Finland & 3.48 & 2.87 \\
\hline
\end{tabular}

In his reply to the Parliamentary question, the South African Minister of Science and Technology indicated that the target of $1 \%$ for GERD/GDP has 'always been considered an interim measure'. In this article, a semi-quantitative approach has suggested a target of $1.62 \%$ as being more appropriate given the present economic status of the country, and its proposed development trajectory. Perhaps we should already be priming our politicians and laying the foundation for this target so that this level of funding can be efficiently and effectively deployed.

\section{References}

[1] Department of Science and Technology; "South Africa's Research and Development Strategy." Department of Science and Technology, Pretoria, 2002.

[2] European Commission; "R\&D investment targets and current trends." downloaded from the European Union site at http://europa.eu.int/comm/research/era/3pct/pdf/rd_investment_snapshot_24sep 04.pdf, September 2004.

[3] European Commission; reference downloaded in September 2006 from the site www.europa.eu.int/comm/research/era/3pct/pdf/ann1.pdf, 2006.

[4] Godin, B.; "The emergence of science and technology indicators: why did governments supplement statistics with indicators?" Project on the History and Sociology of S\&T Statistics, Paper No 8, Montreal, Office on Science and Technology, 2001.

[5] OECD Main Science and Technology Indicators; see for instance http://new.sourceoecd.org/vl=395023/cl=42/nw=1/rpsv/cw $/$ vhosts $/$ oecdthemes $/ 9$ 9980134/v2003n10/contp1-1.htm.

[6] OECD; "Frascati Manual Updated," available from the OECD website at http://www1.oecd.org/dsti/sti/stat-ana/prod/eas_fras.htm, 1999. 
[7] OTA; "Research funding as an investment; can we measure the returns?" Technical Memorandum, Office of Technology Assessment, US Congress, Washington, OTA-TM-SET-36, 1986.

[8] Salter, A. J. and B. R. Martin; "The economic benefits of publicly funded basic research: a critical review." Research Policy, vol. 30(3), pp 509-532, 2001.

[9] Walwyn, D; data obtained from an unpublished survey of R\&D activities in Botswana, undertaken by the CSIR in 2005 and covering the 2004/5 financial year.

[10] Walwyn, D.; "Finland and the mobile phone industry: A case study of the return on investment from government-funded research and development," Technovation, vol. 27, 335-341, 2007. 